\title{
Correction to: Safety and effectiveness of peficitinib (ASP015K) in patients with rheumatoid arthritis: interim data (22.7 months mean peficitinib treatment) from a long-term, open-label extension study in Japan, Korea, and Taiwan
}

Tsutomu Takeuchi ${ }^{{ }^{*}+}$, Yoshiya Tanaka ${ }^{2 \dagger}$, Sakae Tanaka ${ }^{3}$, Atsushi Kawakami ${ }^{4}$, Yeong-Wook Song ${ }^{5}$, Yi-Hsing Chen ${ }^{6}$, Mitsuhiro Rokuda ${ }^{7}$, Hiroyuki Izutsu', Satoshi Ushijima ${ }^{7}$, Yuichiro Kaneko ${ }^{7}$, Yoshihiro Nakashima ${ }^{7}$,

Teruaki Shiomi ${ }^{7}$ and Emi Yamada ${ }^{7}$

Correction to: Arthritis Research \& Therapy (2020) 22:47 https://doi.org/10.1186/s13075-020-2125-2

Following publication of the original article [1], the authors identified an error in the 95\% CI bars plotted on the graphs of Fig. $6 a, b$, and c. The CI numbers in the table below the graph are correct, but the upper and lower limit bars plotted on the graph are incorrect. The corrected Fig. 6 is given below.

\section{Author details}

${ }^{1}$ Keio University School of Medicine, Tokyo, Japan. ${ }^{2}$ University of Occupational and Environmental Health, Japan, Kitakyushu, Japan. ${ }^{3}$ University of Tokyo, Tokyo, Japan. ${ }^{4}$ Nagasaki University Graduate School of Biomedical Sciences, Nagasaki, Japan. ${ }^{5}$ Seoul National University, Seoul National University Hospital, Seoul, South Korea. ${ }^{6}$ Taichung Veterans General Hospital, Taichung, Taiwan. ${ }^{7}$ Astellas Pharma, Inc., Tokyo, Japan.
Published online: 23 June 2020

\section{Reference}

1. Takeuchi T, Tanaka Y, Tanaka S, et al. Safety and effectiveness of peficitinib (ASP015K) in patients with rheumatoid arthritis: interim data (22.7 months mean peficitinib treatment) from a long-term, open-label extension study in Japan, Korea, and Taiwan. Arthritis Res Ther. 2020;22:47. https://doi.org/10. 1186/s13075-020-2125-2.

The original article can be found online at https://doi.org/10.1186/s13075020-2125-2.

*Correspondence: tsutake@z5.keio.jp

These data were presented in part as a poster at the 2019 ACR/ARHP Annual Meeting, November 8-13, 2019, Atlanta, GA and as an oral presentation at the 2019 JCRA Annual Meeting, November 30, 2019, Nagoya, Aichi.

${ }^{\dagger}$ Tsutomu Takeuchi and Yoshiya Tanaka contributed equally to this work. ${ }^{1}$ Keio University School of Medicine, Tokyo, Japan.

Full list of author information is available at the end of the article

C The Author(s). 2020 Open Access This article is licensed under a Creative Commons Attribution 4.0 International License, which permits use, sharing, adaptation, distribution and reproduction in any medium or format, as long as you give appropriate credit to the original author(s) and the source, provide a link to the Creative Commons licence, and indicate if changes were made. The images or other third party material in this article are included in the article's Creative Commons licence, unless indicated otherwise in a credit line to the material. If material is not included in the article's Creative Commons licence and your intended use is not permitted by statutory regulation or exceeds the permitted use, you will need to obtain permission directly from the copyright holder. To view a copy of this licence, visit http://creativecommons.org/licenses/by/4.0/ The Creative Commons Public Domain Dedication waiver (http://creativecommons.org/publicdomain/zero/1.0/) applies to the data made available in this article, unless otherwise stated in a credit line to the data. 


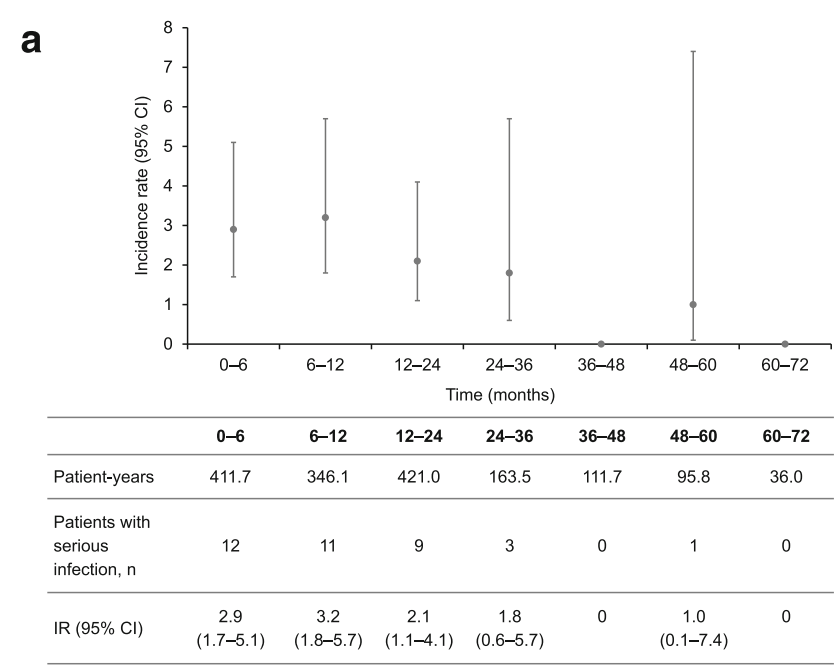

b

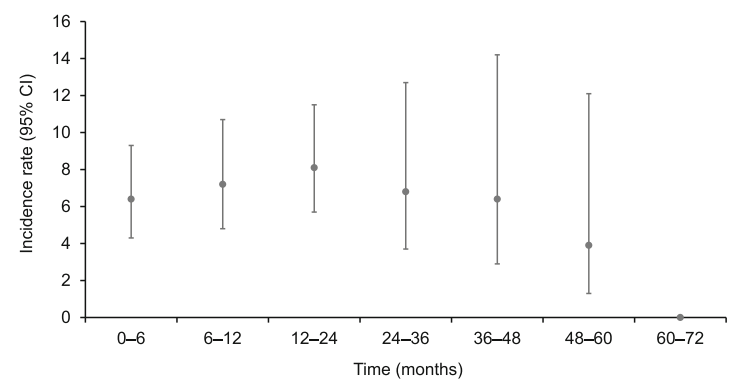

\begin{tabular}{lccccccc}
\hline & $\mathbf{0 - 6}$ & $\mathbf{6 - 1 2}$ & $\mathbf{1 2 - 2 4}$ & $\mathbf{2 4 - 3 6}$ & $\mathbf{3 6 - 4 8}$ & $\mathbf{4 8 - 6 0}$ & $\mathbf{6 0 - 7 2}$ \\
\hline Patient-years & 408.5 & 335.2 & 394.1 & 146.5 & 94.2 & 76.9 & 28.9 \\
\hline $\begin{array}{l}\text { Patients with } \\
\text { herpes zoster- } \\
\text { related disease, } \\
\mathrm{n}\end{array}$ & 26 & 24 & 32 & 10 & 6 & 3 & 0 \\
\hline $\mathrm{IR}(95 \% \mathrm{Cl})$ & $\begin{array}{c}6.4 \\
(4.3-9.3)\end{array}$ & $\begin{array}{c}7.2 \\
(4.8-10.7)\end{array}$ & $\begin{array}{c}8.1 \\
(5.7-11.5)\end{array}$ & $\begin{array}{c}6.8 \\
(3.7-12.7)\end{array}$ & $\begin{array}{c}6.4 \\
(2.9-14.2)\end{array}$ & $\begin{array}{c}(1.3-12.1) \\
\text { (1) }\end{array}$ & 0 \\
\hline
\end{tabular}

C

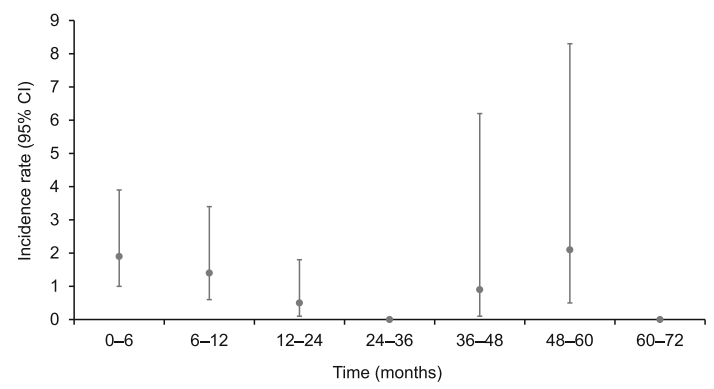

\begin{tabular}{lccccccc}
\hline & $\mathbf{0 - 6}$ & $\mathbf{6 - 1 2}$ & $\mathbf{1 2 - 2 4}$ & $\mathbf{2 4 - 3 6}$ & $\mathbf{3 6 - 4 8}$ & $\mathbf{4 8 - 6 0}$ & $\mathbf{6 0 - 7 2}$ \\
\hline Patient-years & 412.5 & 350.4 & 433.6 & 168.9 & 114.0 & 96.5 & 36.2 \\
\hline $\begin{array}{l}\text { Patients with } \\
\text { malignancies, } \mathrm{n}\end{array}$ & 8 & 5 & 2 & 0 & 1 & 2 & 0 \\
\hline $\mathrm{IR}(95 \% \mathrm{Cl})$ & $\begin{array}{c}1.9 \\
(1.0-3.9)\end{array}$ & $\begin{array}{c}1.4 \\
(0.6-3.4)\end{array}$ & $\begin{array}{c}0.5 \\
(0.1-1.8)\end{array}$ & 0 & $\begin{array}{c}0.9 \\
(0.1-6.2)\end{array}$ & $\begin{array}{c}2.1 \\
(0.5-8.3)\end{array}$ & 0 \\
\hline
\end{tabular}

Fig. 6 Adverse events of special interest per 100 patient-years during the overall period: a serious infections, b herpes zoster-related disease, c malignancies (SAF). Patient-years was calculated from initial dose up to first incidence of the event for patients who had at least one event, and from initial dose through follow up for patients who had no events; IR was calculated as (100 $\times$ number of patients with $\geq 1$ incidence/total patient-years) Cl confidence interval, $\mathbb{R}$ incidence rate 